\title{
Article
}

\section{Portable FRET-based biosensor device for on-site lead detections}

\author{
Wei-Qun Lai ${ }^{1,2}$, Yu-Fen Chang ${ }^{3}$, Fang-Ning Chou ${ }^{1}$ and De-Ming Yang ${ }^{1,2, *}$ \\ 1 Microscopy Service Laboratory, Basic Research Division, Department of Medical Research, Taipei Veterans \\ General Hospital, Taipei, Taiwan; dmyang@vghtpe.gov.tw \\ 2 Institute of Biophotonics, School of Biomedical Science and Engineering National Yang Ming Chiao Tung \\ University, Taipei, Taiwan; yang.deming2021@nycu.edu.tw \\ 3 LumiSTAR Biotechnology, Inc., Taipei City 115, Taiwan; yu-fen.chang@lumistar.com.tw \\ * Correspondence: dmyang@vghtpe.gov.tw
}

\begin{abstract}
Most methods for measuring environmental lead $(\mathrm{Pb})$ content are time consuming, expensive, hazardous, and restricted to specific analytical systems. To provide a facile, safe tool to detect $\mathrm{Pb}$, we created pMet-lead, a portable fluorescence resonance energy transfer (FRET)-based Pb biosensor. pMet-lead comprises a 3D-printed frame housing a 405-nm laser diode - an excitation source for fluorescence emission images (YFP and CFP) - accompanied by optical filters, a customized sample holder with a Met-lead 1.44 M1 (the most recent version)-embedded biochip, and an optical lens aligned for smartphone compatibility. Measuring the emission ratios ( $\mathrm{Y} / \mathrm{C})$ of the FRET component enables $\mathrm{Pb}$ detection with a dynamic range of nearly 2 (1.96), pMet-lead/Pb dissociation constant $\left(\mathrm{K}_{\mathrm{d}}\right) 36.53 \mathrm{nM}$, and limit of detection $50 \mathrm{nM}(1 \mu \mathrm{g} / \mathrm{dL}, 10 \mathrm{ppb})$. To mitigate earlier problems with lack of selectivity for $\mathrm{Pb}$ vs. zinc, we preincubated samples with tricine, a low-affinity zinc chelator. We validated pMet-lead measurements of characterized laboratory samples and unknown samples from six regions in Taiwan by inductively coupled plasma mass spectrometry (ICP-MS). Notably, two unknowns had $\mathrm{Y} / \mathrm{C}$ ratios significantly higher than that of the control $(3.48 \pm 0.08$ and $3.74 \pm 0.12$ vs. $2.79 \pm 0.02$ ), along with $\mathrm{Pb}$ concentrations (10.6 ppb and $15.24 \mathrm{ppb}$ ) above the WHOpermitted level of $10 \mathrm{ppb}$ in tap water, while the rest four unknowns showing no detectable $\mathrm{Pb}$ upon ICP-MS. These results demonstrate that pMet-lead provides a rapid, sensitive means for on-site $\mathrm{Pb}$ detection in water from the environment and in living/drinking supply systems to prevent potential $\mathrm{Pb}$ poisoning.
\end{abstract}

Keywords: lead biosensors; FRET; portable Pb sensor; smartphone-based device; Met-lead; tap water lead; groundwater lead

\section{Introduction}

More than 800 million children in the world live in toxic environments containing the heavy metal lead $(\mathrm{Pb})[1]$. Although the measurement of blood lead level (BLL) is the only officially approved way to evaluate the extent of $\mathrm{Pb}$ exposure within a person's body, long-term studies on $\mathrm{Pb}$ poisoning raise questions about the so-called safe levels in children; a BLL as low as $5 \mu \mathrm{g} / \mathrm{dL}$ in the young population is still dangerous if it is chronic [24]. Toxic $\mathrm{Pb}$ may be continuously supplied through leaded pipes or other unknown source; drinking water contaminated with $\mathrm{Pb}$ even at concentrations as low as $10 \mathrm{ppb}$ cause health problems that, sadly, go undetected in many parts of the world [5]. To avoid the silent and irreversible damage of $\mathrm{Pb}$ in the general population, low-cost and highly accurate $\mathrm{Pb}$ detection devices for both environmental and biological (blood or urine) samples are urgently needed. Such devices will increase awareness of the threat of $\mathrm{Pb}$ poisoning through daily activities involving drinking, eating, and contact.

We have spent years developing and optimizing workable $\mathrm{Pb}$ biosensors, i.e., genetically encoded fluorescent protein biosensors [6-9]. The sensitivity (limit of detection, LOD) of the best Pb biosensor, Met-lead 1.44 M1, can be as low as $10 \mathrm{nM}$ (around $0.2 \mu \mathrm{g} / \mathrm{dL}$ or $2 \mathrm{ppb}$ ) [8], which is sufficient for use with real samples, e.g. to determine BLL from subjects with suspected lead exposure and to assess tap water for conformity to the World 
Health Organization (WHO) limit for $\mathrm{Pb}$ (10 ppb) [10]. Thus, the application of this optimized $\mathrm{Pb}$ biosensor for general use will benefit the world's population.

The development of many portable sensing devices has progressed hand in hand with smartphone technology, especially with the advent of $4 \mathrm{G} / 5 \mathrm{G}$ internet connectivity. The in-built complementary metal-oxide-semiconductor (CMOS) camera (with $2048 \mathrm{x}$ 1536 or more pixels) as the signal/image recorder, with either simple or complex optics, within smartphones (e.g. Nokia N73, PureView 808; Sony-Ericsson U10i AinoTM; iPhone 2G, 4G, 4S, 5 etc.) can be combined with additional suitable optical components and materials. Lenses (objective or ball lens), illumination sources (lasers or light-emitting diodes, LEDs), microfluidic channels (for small-volume samples), 3-D printed frame structures, and computer programs or algorithms can be used with smartphones to capture images of interest for a variety of purposes, such as counting the number of targeted objects. For advanced biomedical applications, clear bright-field and/or fluorescence images with appropriate magnification (from 7x, 10x, 28x to 350x), spatial resolution (from 1.2 to $20 \mu \mathrm{m}$ ), and field of view (FOV; from $150 \mu^{2}$ to $180 \mathrm{~mm}^{2}$ ) can be acquired through smartphonebased devices at low cost [11-15]. Such smartphone-based devices have been applied in a variety of biomedical and environmental settings [16], such as the detection of glucose [17], ATP [18], inorganic phosphate [19], mercury (Hg) [20], and even certain cancer cells [21], as well as viruses such as human immunodeficiency virus type 1 (HIV-1) [22] and severe acute respiratory syndrome coronavirus 2 (SARS-CoV-2) [23].

In this study, we built a portable $\mathrm{Pb}$ sensing device, pMet-lead, that can promptly detect $\mathrm{Pb}$ in samples by acquiring the ratiometric $\mathrm{Y} / \mathrm{C}$ FRET signals from the optimized $\mathrm{Pb}$ biosensor Met-lead 1.44 M1. In this way, the presence of $\mathrm{Pb}$ in environmental water sources, such as tap water or groundwater, can be revealed in real time.

\section{Materials and Methods}

\subsection{Instrumentation of the portable FRET-based Pb biosensor device ( $p M e t-l e a d$ )}

The 3D design of the FRET-based portable device for $\mathrm{Pb}$ detection was carried out through 3D graphing using Fusion360 (Autodesk), according to the specifications of the selected smartphone, sample holder, and optical distance for fluorescent signal recording. The size of the device is around $190 \mathrm{~mm} \times 140 \mathrm{~mm} \times 105 \mathrm{~mm}(\mathrm{~L} \times \mathrm{W} \times \mathrm{H}$; Figure 1 and Figure S1). Through the additive manufacturing (AM) technique, two printer machines, CR-5 Pro (Creality 3D Inc.) and CR-8 (Creality 3D Inc.), were used. The printing material polylactide (PLA) was applied at a printing temperature range of $190-215^{\circ} \mathrm{C}$, under the control of Cura software (Ultimaker Inc.). The overall procedure for making this device takes around 50 hours.

\subsection{Preparing of the Met-lead-containing biochip}

Single human living cells from different sources were used to examine the sensing ability of Met-lead biosensors. Human cell lines-human embryonic kidney cells (HEK 293) and human cancer cells (HeLa) - were from the American Type Culture Collection (ATCC, Rockville, MD). They were cultured according to the culture manual [6, 24] and were then ready for final observation with Tyrode's buffer. For further FRET ratio imaging, all the human cells were seeded on $24 \mathrm{~mm}$ coverglasses (Deckglaser) coated with poly-L-lysine and were transfected with the gene encoding Met-lead using LipofectAmine (Invitrogen, Thermo Fisher Scientific Inc.) according to the manual [6, 8, 24-25]. The cells were used for lead biosensing 2 days after transfection.

\subsection{Sample source and preparation}

The sources of tested samples were obtained from water supply systems, such as tap water or groundwater for drinking and other living usage. Tap water and groundwater were collected from an inhabited area near Taipei (Taoyuan County) and from a rural area of Taiwan (Dongshi Township, Yunlin County). For standard samples, different 
concentrations of $\mathrm{Pb}$ solutions $(1,10,50$ and $100 \mathrm{nM}$ and 1 and $10 \mu \mathrm{M})$ were prepared as previously described [8]. Sample were prepared for validation (section 2.6) as described previously [8].

\subsection{Ratio imaging under epifluorescence FRET microscope}

Met-lead expressing cells were placed on an inverted live-cell FRET microscope [7, 8, 10]. To detect the epifluorescence signals of cp173Venus (yellow fluorescent protein; YFP) and ECFP $(\triangle \mathrm{C} 11)$ (enhanced cyan fluorescent protein; CFP) from Met-lead, the FRET emission (Y/C) ratio image system was equipped with an inverted microscope (Axiovert 200M; with 10x objectives, NA = 0.3, Zeiss, Germany), a W-View module (Gemini, Hamamatsu, Japan; with emission filters 542/27 nm for YFP and 483/32 nm for CFP), and a CMOS camera (ORCA-Flash 4.0 LT, Hamamatsu, Japan) controlled by the HCImage software. The YFP (530-630 nm) and CFP (460-500 nm) emission signals were acquired continuously through the $\mathrm{W}$-View module $[7,8,10]$.

\subsection{Ratio imaging under pMet-lead}

For portable FRET ratio imaging, biochips containing Met-lead were placed into the sample holder of pMet-lead as described in section 2.1, with a $405 \mathrm{~nm}$ laser used as the excitation source. To make it possible to obtain the emission signals of cp173Venus and $\operatorname{ECFP}(\triangle \mathrm{C} 11)$ from a biochip containing Met-lead, the device contains switchable filters, $542 / 27 \mathrm{~nm}$ and $483 / 32 \mathrm{~nm}$, for YFP and CFP, respectively. The fluorescent signals were recorded using the built-in camera in the smartphone (ZenPhone 4, Asus, Taiwan; or Mi115G, Mi, China), which was controlled by an app capable of collecting raw data (10bit images). The emission signals of YFP (530-630 nm) and CFP (460-500 nm) were acquired separately. Before the $\mathrm{Y} / \mathrm{C}$ ratio is calculated and data are displayed from the iMetlead program in a MATLAB environment (Figure 2) and/or on a smartphone (Figure S2B), the images taken from the smartphone are pre-processed through an algorithm:

$\mathrm{Y}(\mathrm{I})=1 / 4(Y(i-1, j)+Y(i+1, j)+Y(i, j-1)+Y(i, j+1)),[\mathrm{Y}(\mathrm{I})<200, \mathrm{i}=2$ :length, $\mathrm{j}=2$ :weight $]$

$C(\mathrm{I})=1 / 4(C(i-1, j)+C(i+1, j)+C(i, j-1)+C(i, j+1)),[C(\mathrm{I})<150, \mathrm{i}=2:$ length, $\mathrm{j}=2$ :weight $]$

and

$R(\mathrm{I})=1 / 4(R(i-1, j)+R(i+1, j)+R(i, j-1)+R(i, j+1)),[\mathrm{R}(\mathrm{I})<1, \mathrm{i}=2:$ length, $\mathrm{j}=2$ :weight $]$

\subsection{Validation of the $\mathrm{Y} / \mathrm{C}$ ratio data from pMet-lead}

Samples from both laboratory and real environments, such as tap water, were tested by the general standard method, i.e., inductively coupled plasma mass spectrometry (ICPMS); the tests were performed within the Division of Clinical Toxicology and Occupational Medicine, Taipei Veterans General Hospital.

\subsection{Data analysis}

ImageJ was used to combine the ratio of fluorescent signals of cp173Venus and $\operatorname{ECFP}(\triangle \mathrm{C} 11)$ (ratio plus) and displayed with rainbow color plate to visualize the FRET biosensing from blue to red (look-up table, LUT) within tested biochips. All experiments were carried out three times with at least three different sets of tested samples (tap water or groundwater). Data gathered from the different batches of Met-lead biochips on different samples were integrated to calculate the emission $(Y / C)$ ratio. Significant changes were indicated based on $\mathrm{p}$ value calculated using a two-tailed t-test function contained in the IBM SPSS statistics. The mean differences are described as significant at the $0.0005\left(^{* * *}\right)$ or $\left.0.005{ }^{* *}\right)$ level.

\section{Results}

\subsection{Design and outline of the portable FRET-based Pb biosensor device ( $p M e t-l e a d)$}

Building on previous successes with FRET-based Pb biosensing using Met-leads [7, $8,10]$, we designed and manufactured a portable device (the pMet-lead) that is compatible 
with smartphones and has the capacity to acquire $\mathrm{Y} / \mathrm{C}$ emission ratio images from Metleads or other FRET biosensors (Figure 1 and Figure S1 in detail). Our aim in building this portable FRET device was to allow FRET biosensing to be performed without the need for special FRET microscopes, which are only available in research or hospital laboratories. This pMet-lead device comprises two parts: (1) A Pb sensing device (Figure 1A and 1B) containing a pair of illumination sources, an LED (for bright-field images; BF in Figure 1C) and a $405 \mathrm{~nm}$ laser diode (for the donor excitation during the FRET ratio biosensing); a pair of convex lenses; a sample holder with biochip for Pb biosensing; and emission filters (for obtaining the $\mathrm{Y} / \mathrm{C}$ ratio images, Figure $1 \mathrm{C}$ ). We performed functional tests of the biochips containing the Met-lead biosensors in regard to both imaging and sensing ability under a well-defined FRET microscope (Figure S2A). (2) A holder to contain an Android smartphone linked to iMet-lead driven either by notebooks through a USB connection in a MATLAB environment (Figure 2) or by smartphones with an appropriate app preinstalled (Figure S2B). To complete the setup of this smartphone-based Pb sensing device, we seeded the cells expressing Met-lead 1.44 M1 onto the biochip and inserted it into the device (Figure 1, Figure S1 and Figure 2C).

A

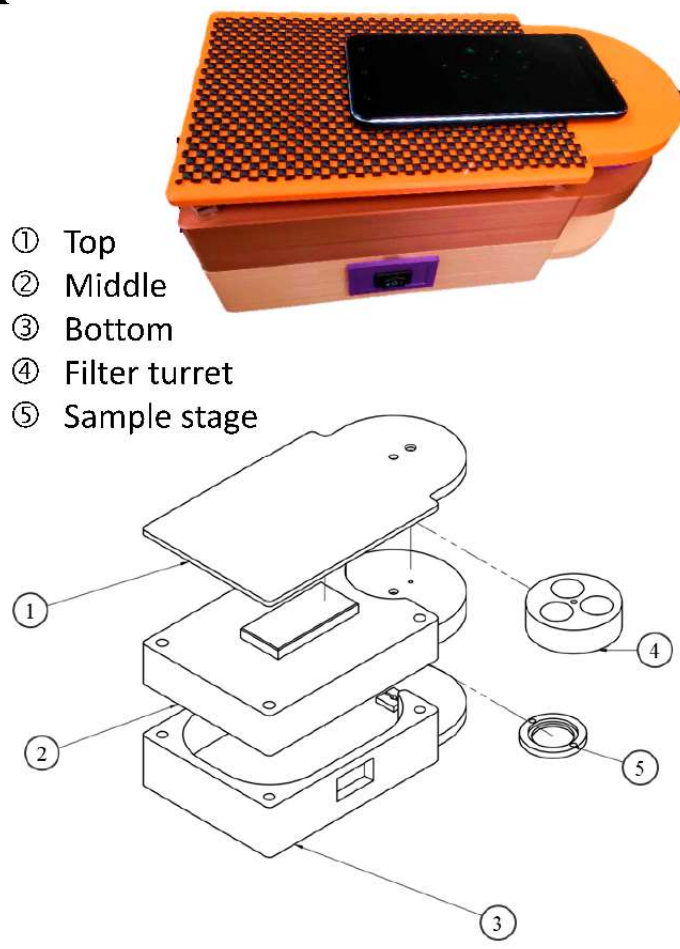

B

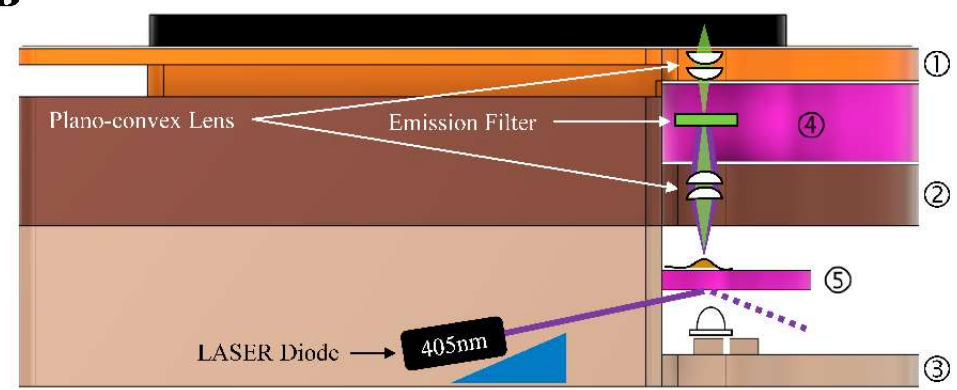

C

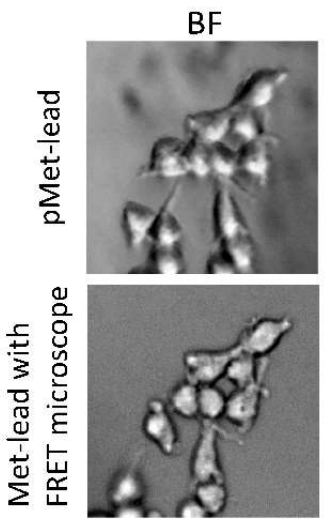

CFP

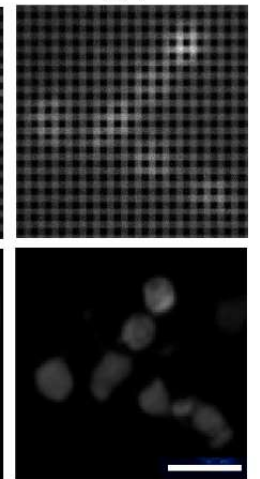

Figure 1. Design and layout of the portable FRET-based Pb sensing device (pMet-lead) and examples of images generated with the pMet-lead compared to conventional FRET ratio imaging. (A) General setup of pMet-lead: 1. the top plate holds the smartphone; 2 . the middle part of the apparatus contains the plano-convex lens and is linked to the filter turret (part 4); 3. the bottom part contains the illumination sources and is linked to the sample stage (part 5); 4 . the filter turret contains two emission fluorescence filters that receive YFP and CFP emission signals (changeable according to various FRET pairs); 5 . the sample stage receives the biochip containing the cells expressing the Met-lead biosensor. (B) Side view of the optical design of pMet-lead. (C) The representative bright-field (BF, left) and fluorescence (YFP, middle; CFP, right) images of the Pb biosensor-expressing HEK293 cells obtained with pMet-lead (above) or under a FRET microscope (with $10 \mathrm{x}$ objective; below). Scale bar, $30 \mu \mathrm{m}$.

As pMet-lead can obtain both BF and fluorescence (YFP and CFP) images of the $\mathrm{Pb}$ biosensor - the Met-lead-coated biochip - with a smartphone camera (Figure 1), the next step toward portable $\mathrm{Pb}$ detection was to enable the device to register the presence of $\mathrm{Pb}$ through analysis of the YFP/CFP ratios from the $\mathrm{Pb}$ biosensor, as previously demonstrated $[7,8,10]$. To detect $\mathrm{Pb}$ from samples, we developed a software package (for notebooks) and an app (for smartphones), both called iMet-lead, that perform the $\mathrm{Y} / \mathrm{C}$ ratio 
transformation step described in the flowchart in Figure 2A (Figure S2B); this step can be controlled using the options provided on the iMet-lead interface. The visualized ratios (displayed in rainbow color; Figure 2B) derived from the YFP and CFP images obtained with the smartphone camera can be easily interpreted by the surveyor in real time through the iMet-lead interface (Figure 2B, Figure S2B). Fig. 2C demonstrates the full procedure for using pMet-lead for fast detection of $\mathrm{Pb}$ in environmental water or water supply systems, such as tap water (for drinking) and groundwater. Overall, pMet-lead can quickly process the images representing $\mathrm{Pb}$ levels and report the presence of $\mathrm{Pb}$ on the notebook or smartphone screen.

A

B
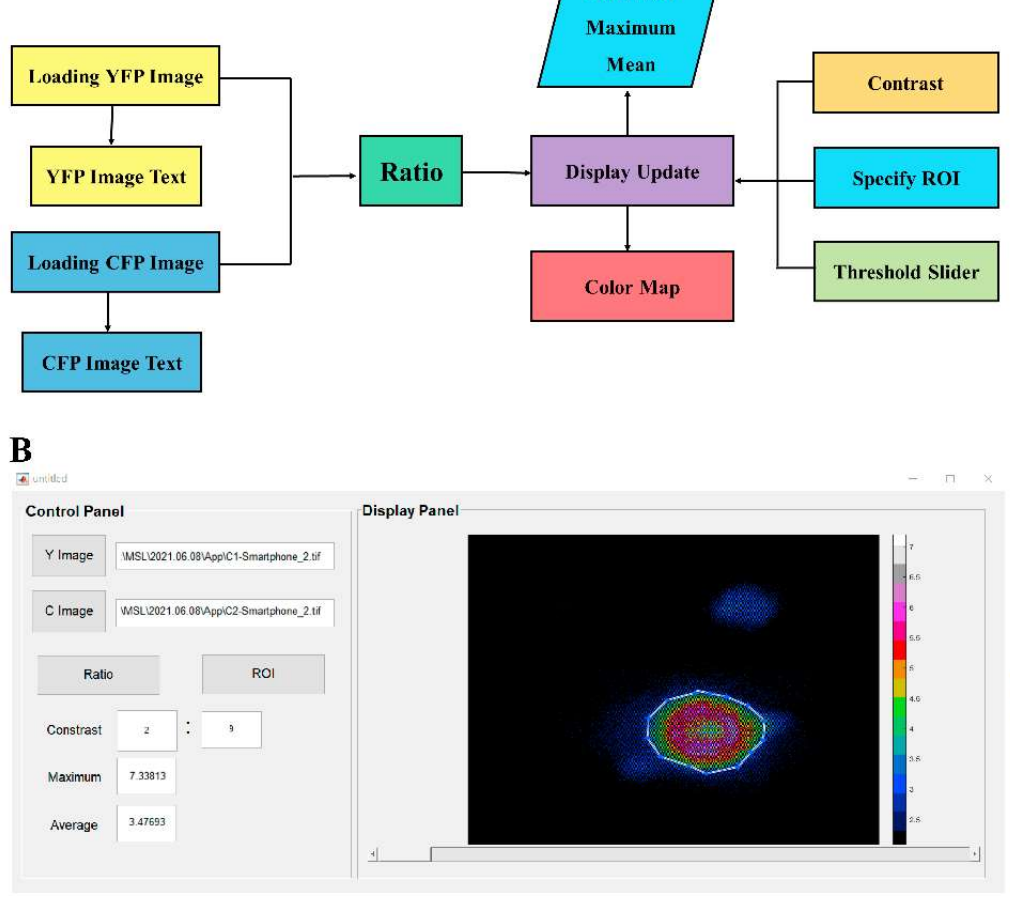

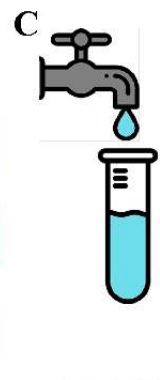

\section{西}

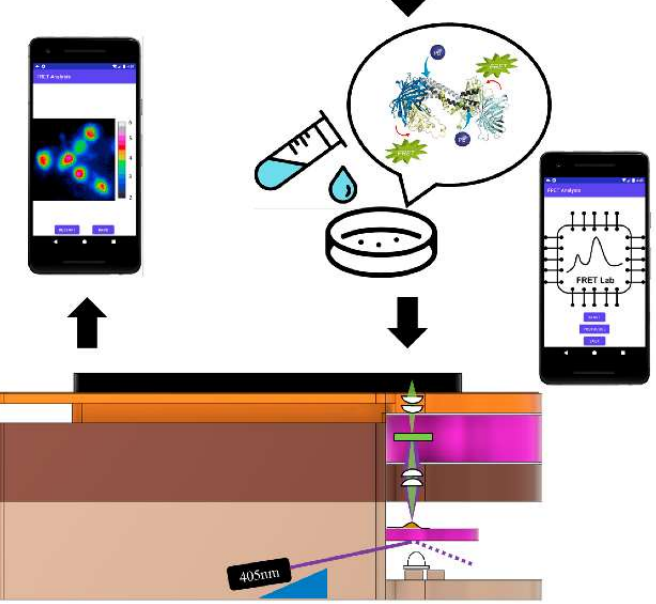

Figure 2. Processing of fluorescence images in pMet-lead. (A) Flowchart of the computational window graphical user interface (GUI) for ratio color imaging. After image input (Loading) of YFP and CFP, select Ratio to make and save the ratio images to temporary memory sites. The calculated ratios will be displayed in a rainbow color format (Display Update; Color Map; Maximum Mean). The ranges of selected regions of interest (ROIs) can be manually adjusted to show the best present status (Specify ROI; Contrast; Threshold Slider). (B) Screen shot of the GUI for the FRET-based device interface during $\mathrm{Pb}$ sensing. The ratio color bar represents YFP/CFP ratios from 2 (black) to 7 (white). (C) The whole procedure for on-site $\mathrm{Pb}$ sensing with the pMet-lead.

\subsection{Performance of pMet-lead}

Built-in smartphone cameras have a depth of 8 bits $\left(2^{0}-2^{8}\right.$, which is a relatively small dynamic range) in each RGB channel for displaying color images (Figure S3A). In contrast, scientific-grade cameras produce images with at least 12 bits $\left(2^{0}-2^{12}\right.$, providing a relatively large dynamic range) in monochrome format. However, some smartphones produce images with a depth of more than 10 bits, but only in the raw data format (DNG). Thus, we acquired the fluorescent images of samples from the cameras of smartphones by extracting the DNG-format files (Figures S3B, 3C and 3D). However, upon close inspection of the fluorescent images taken from pMet-lead processing, repeated black spots could be found in both YFP and CFP channels (Figure 3A). These spots in the DNG file format seemed not to derive from the device itself (Figure S3E) and could generate large errors in the Y/C ratios, since they are not true fluorescence signals from the Met-lead biosensor; they may also be the cause of the poor image quality of $\mathrm{Y} / \mathrm{C}$ ratio color images (Figure 3A). Therefore, as an alternative to using DNG files, we figured out a method/function, as described 
in section 2.5, to recalculate the signals from the YFP and CFP channels together (Figure $3 \mathrm{~B}$ ); this was similarly used to correct the $\mathrm{Y} / \mathrm{C}$ ratio taken from pMet-lead (Figure $3 \mathrm{C}$ ). We found that this preprocessing improved the quality of both the fluorescent and $\mathrm{Y} / \mathrm{C}$ ratio color images sufficiently to enable further characterization of the sensing ability of pMetlead (Figure 3D).

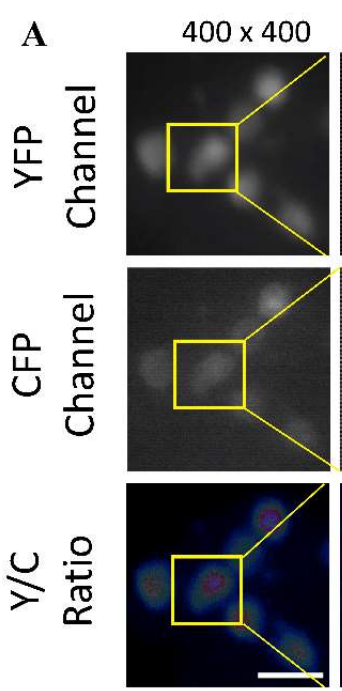

D
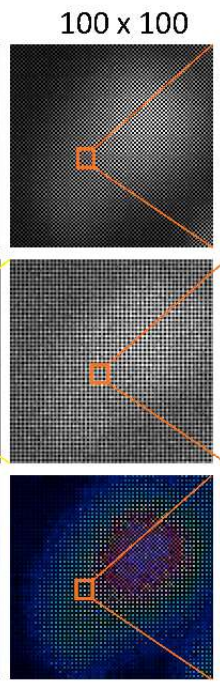

Original
$10 \times 10$

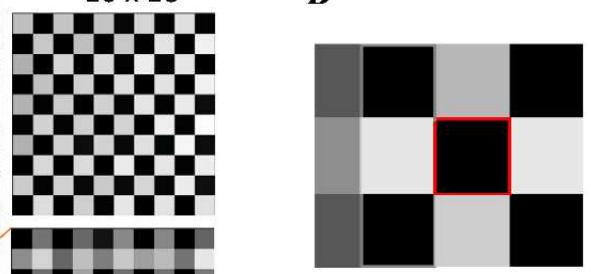

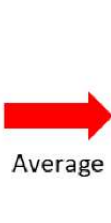

C
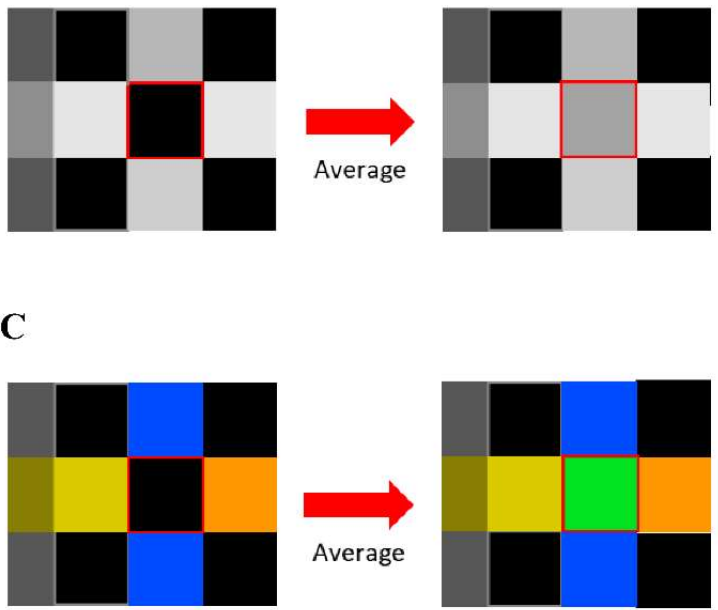

Pre-processed
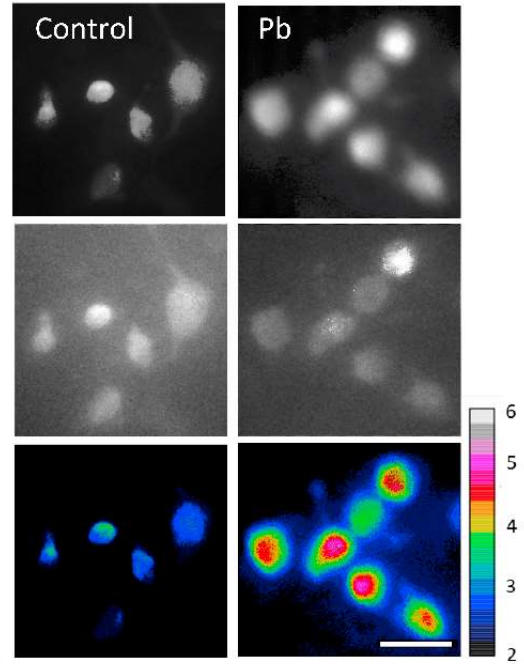

Figure 3. Pre-processing of pMet-lead fluorescence images taken with a smartphone camera. (A) Met-lead-expressing cells taken from pMet-lead are first separated into YFP and CFP channels. The Y/C ratio image is obtained through the division of fluorescence from the YFP and CFP channels. Selected regions of YFP, CFP, and Y/C ratio from an image size of $400 \times 400$ pixels (left) were further magnified to $100 \times 100$ pixels (middle) and $10 \times 10$ pixels (right). The black spots can be observed from both the YFP and CFP channels. (B) and (C) A conceptual illustration of the function of the image processing step described in section 2.5 to fill black spots with signals from adjacent regions of fluorescent YFP or CFP signals (B), or $\mathrm{Y} / \mathrm{C}$ ratios (C). (D) Comparison of images without (Control) or with $\mathrm{Pb}(100 \mathrm{nM})$ taken from pMet-lead without (Original) and with (Pre-processed) corrections as described in section 2.5. Scale bars, $30 \mu \mathrm{m}$. The ratio color bars are from 2 to 5 for the original images (left) and from 2 to 6 for the pre-processed images (right).

We put the biochip containing the Met-lead 1.44 M1 expressing HEK 293 cells into the device and proceeded with $\mathrm{Pb}$ sensing (Figure 4). Similar to previous observations (Figure 1C), including the pre-processing step led to better fluorescent images from the YFP and CFP channels of the Met-lead biosensor, as shown on the screen of the 
notebook/smartphone (Figure $4 \mathrm{~A}$ ). The $\mathrm{Y} / \mathrm{C}$ ratio color images of the same captured field was also promptly generated $(\mathrm{Y} / \mathrm{C}$ ratio of Fig. $4 \mathrm{~A})$. The emission ratios within the Metlead-expressing samples are around $2.7969 \pm 0.1001$ for water without $\mathrm{Pb}$ (control condition, basal level). When various concentrations of $\mathrm{Pb}$ were presented, the ratios increased significantly from $2.9136 \pm 0.800(1 \mathrm{nM}), 2.8310 \pm 0.0112(10 \mathrm{nM})$ to $4.3811 \pm 0.0994(50 \mathrm{nM})$, $4.8107 \pm 0.0470(100 \mathrm{nM}), 5.1732 \pm 0.0298(1 \mu \mathrm{M})$, and up to $5.5572 \pm 0.0138(10 \mu \mathrm{M})$ (Fig. $4 \mathrm{~B})$. Based on these results, we determined that the dynamic range of this new $\mathrm{Pb}$-sensing device was 1.96 . The linearity $\left(\mathrm{R}^{2}\right)$ of known samples for ICP-MS to pMet-lead was 0.8873 (Figure 4C). Through titration experiments, we determined that the dissociation constant $\left(\mathrm{K}_{\mathrm{d}}\right)$ of the Met-lead 1.44 M1 biosensor for Pb in this device was $36.532 \mathrm{nM}$ (Figure S4A), similar to that reported for Met-lead 1.44 M1 on a FRET microscope with 20x objectives (25.97 $\mathrm{nM}$ ) [8]. The LOD of Met-lead 1.44 M1 for Pb in a high-cost FRET microscope is 10 $\mathrm{nM}$ [8], while the LOD of the new portable device was $50 \mathrm{nM}$ (Figure 4A and 4B). The data from pMet-lead at different concentrations of $\mathrm{Pb}$ were further validated by ICP-MS (Figure 4D). The ratio was $2.8310 \pm 0.0112$ at around $2.85 \mathrm{ppb}(10 \mathrm{nM}), 4.3811 \pm 0.0994$ at 11.18 ppb (50 nM), and $4.8107 \pm 0.0470$ at $23.35 \mathrm{ppb}(100 \mathrm{nM})$ (Table 1).
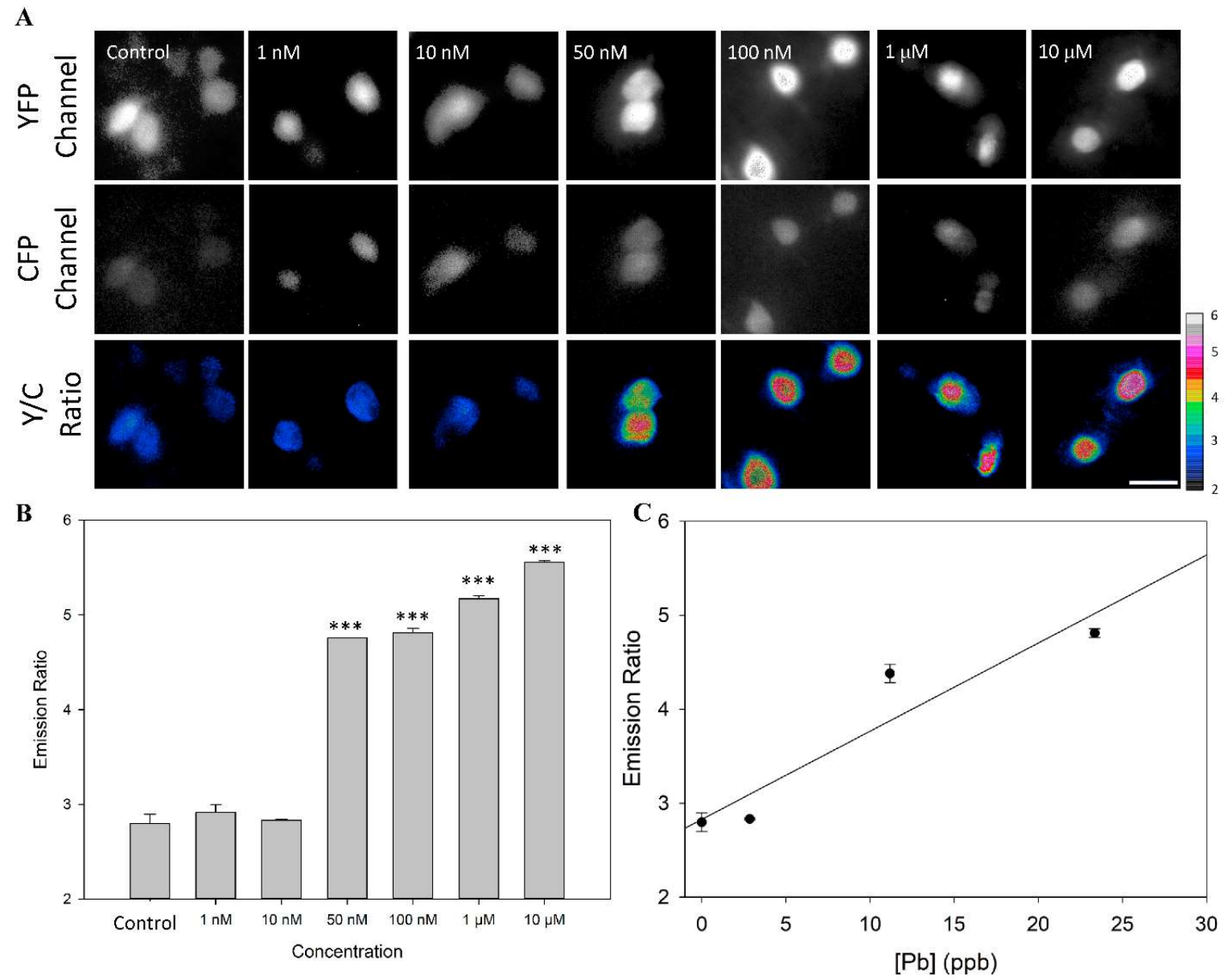

Figure 4. Sensing ability of pMet-lead. (A) The representative pMet-lead FRET ratio images of HEK 293 cells expressing Met-lead 1.44 M1 taken at various concentrations of $\mathrm{Pb}$ from $\mathrm{nM}(1,10,50$, and $100 \mathrm{nM})$ to $\mu \mathrm{M}$ ranges $(1$ and $10 \mu \mathrm{M})$. The fluorescence images of Met-lead 1.44 M1 in the YFP and CFP channels and the ratio color images (through the pre-processing procedure described in Figure 3) under CFP-specific illumination (405 nm). (B) Bar graphs of FRET ratio at various concentrations of $\mathrm{Pb}$ using pMet-lead analysis. (C) Validation of pMet-lead ( $\mathrm{Y} / \mathrm{C}$ emission ratio) using ICP-MS (Pb measured in $\mathrm{ppb})$ at various concentrations of $\mathrm{Pb}(10,50$, and $100 \mathrm{nM})$. Scale bar, $30 \mu \mathrm{m}$. The ratio color bar is from 2 to 6 .

Table 1. Validation of pMet-lead on $\mathrm{Pb}$ measurements. The FRET ratios obtained from pMet-lead Pb measurements of various sources of water (Figure 4) were validated by the general standard method (ICP-MS). 


\begin{tabular}{ccc}
\hline Water samples & Mean of Y/C ratio (with standard error) & ICP-MS (ppb) \\
\hline Control & $2.7969 \pm 0.1001$ & NA $^{1}$ \\
\hline $1 \mathrm{nM}$ & $2.9136 \pm 0.0800$ & NA \\
\hline $10 \mathrm{nM}$ & $2.8310 \pm 0.0112$ & 2.85 \\
\hline $50 \mathrm{nM}$ & $4.3811 \pm 0.0994\left({ }^{* * *}\right)^{2}$ & 11.18 \\
\hline $100 \mathrm{nM}$ & $4.8107 \pm 0.0470\left({ }^{* * *}\right)^{2}$ & 23.35 \\
\hline $1 \mu \mathrm{M}$ & $5.1732 \pm 0.0298\left(^{* * *}\right)^{2}$ & 231.45 \\
\hline $10 \mu \mathrm{M}$ & $5.5572 \pm 0.0138\left(^{* * *}\right)^{2}$ & 2327.71 \\
\hline
\end{tabular}

${ }^{1} \mathrm{NA}$ : none detected; ${ }^{2}$ The values are above the WHO 2017 cutoff for Pb in tap water of $1 \mu \mathrm{g} / \mathrm{dL}(10 \mathrm{ppb}, 50 \mathrm{nM}) ;{ }^{* * *}, \mathrm{p}<0.0005$, two-tailed t-test

\subsection{Solution to the selectivity issue of Met-leads and pMet-lead}

In the first version of Met-lead we developed (Met-lead 1.59), the sensor's selectivity for zinc $(\mathrm{Zn})$ as well as $\mathrm{Pb}$ ions posed a problem [6], and this remained a concern with the newer version (1.44 M1) [8]. Therefore, in order to perform practical testing of the Metlead 1.44 M1 biosensor for detecting environmental $\mathrm{Pb}$, we had to overcome the $\mathrm{Zn}$ interference. We tested whether the use of tricine, a low-affinity Zn chelator [26-27] that does not bind $\mathrm{Pb}$, could mitigate this problem. We found that a test of pure water containing Zn $(11 \mu \mathrm{M}$, or around $1500 \mu \mathrm{g} / \mathrm{dL}$; three times higher than the U.S. EPA regulation of 500 $\mu \mathrm{g} / \mathrm{dL}$, or $5 \mathrm{ppm}$, or $3.33 \mu \mathrm{M}$ ) with Met-lead 1.44 M1 led to an increase in Y/C ratio from a resting value of $1.6008 \pm 0.0451$ to $2.4474 \pm 0.1034$ (solid line in Figure 5A; full time scale in Figure S5). A $11 \mu \mathrm{M}$ solution of $\mathrm{Zn}$ in water sample that was pre-incubated with tricine $(10 \mathrm{mM})$ yielded a significantly lower ratio increase, from $1.6225 \pm 0.0374$, but it remained around $1.7400 \pm 0.0375$, indicating that the increase in ratio was $\mathrm{Zn}$-induced (dash line in Fig. 5A; full time scale in Figure S5). The pre-incubation of tricine $(10 \mathrm{mM})$ and $\mathrm{Pb}(10 \mu \mathrm{M})$ with the same $\mathrm{Zn}$-containing water sample elevated the ratio from $1.7388 \pm 0.060$ up to $3.1545 \pm 0.1102$ (dotted line in Figure 5; full time scale in Figure S5), demonstrating that the sensor could still sense $\mathrm{Pb}$. The averaged data summarizing the tricine tests indicate that tricine could be a good adjuvant for $\mathrm{Pb}$ detection through the Met-lead $\mathrm{Pb}$ biosensor (Figure 5B). 
A
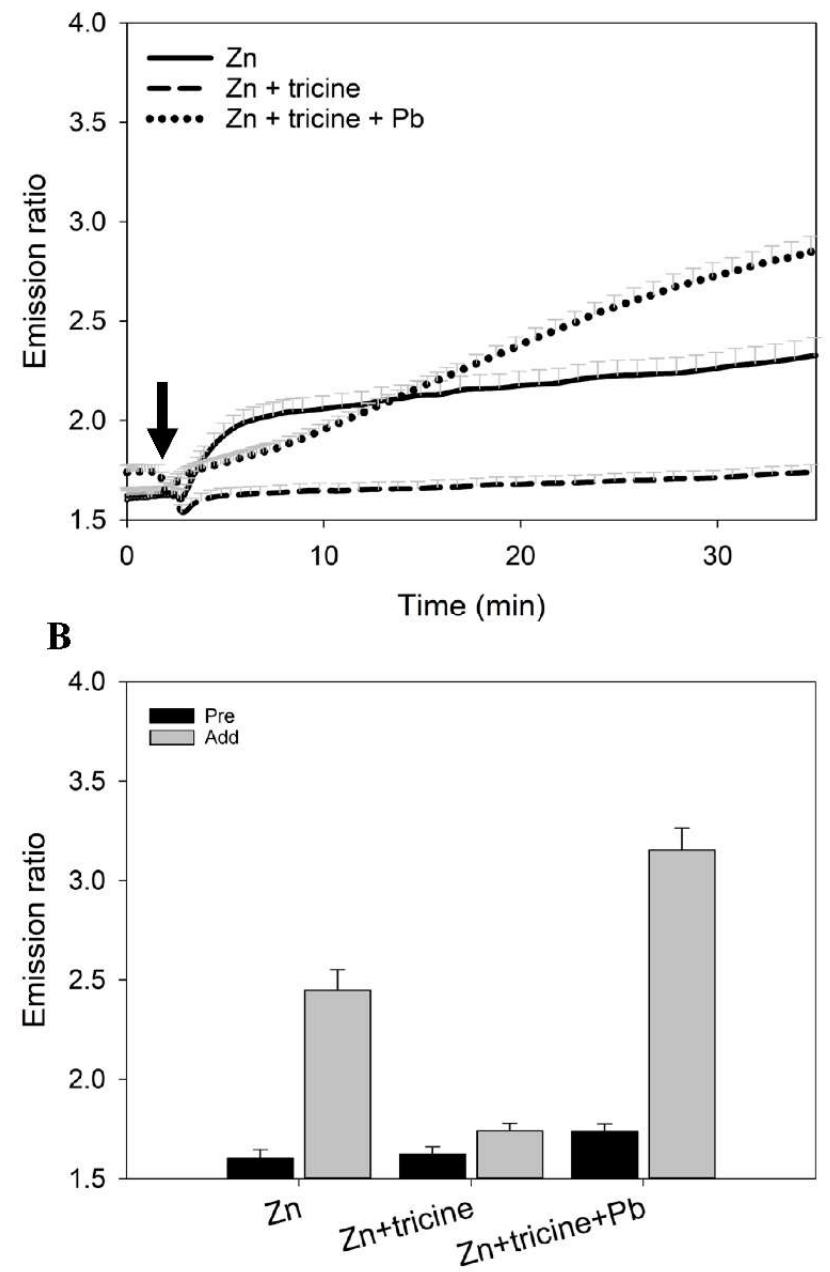

C

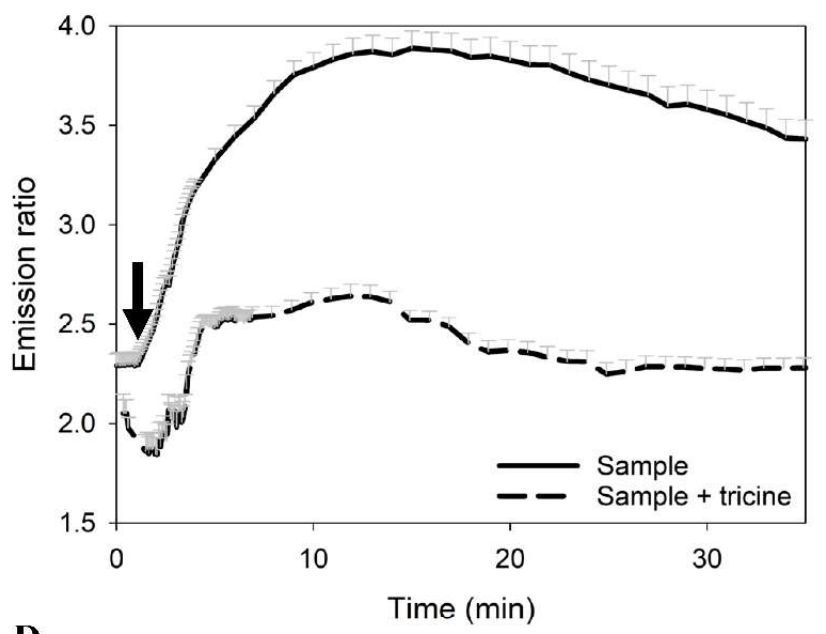

D

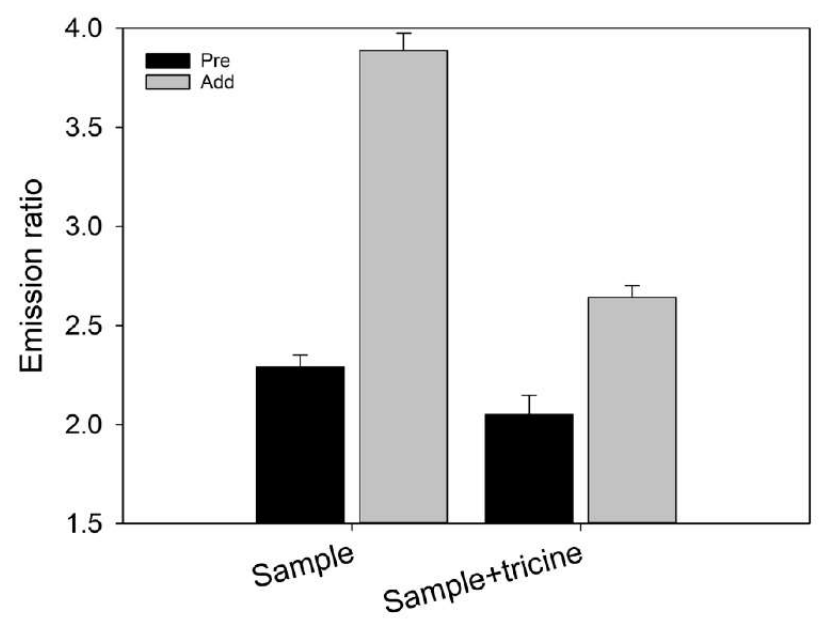

Figure 5. Removal of zinc with tricine enables practical $\mathrm{Pb}$ sensing by pMet-lead. (A) Time-lapse of the emission ratio (YFP/CFP) recorded by the Met-lead biosensing system. Double-distilled water (Distillation-Distillation $\mathrm{H} 2 \mathrm{O}, \mathrm{ddH} 2 \mathrm{O}$ ) from the laboratory was pre-mixed with $11 \mu \mathrm{M}$ zinc alone ( $\mathrm{Zn}$; solid line), $11 \mu \mathrm{M}$ zinc and $10 \mathrm{mM}$ tricine ( $\mathrm{Zn}+$ tricine; dashed line), or $11 \mu \mathrm{M}$ zinc, $10 \mathrm{mM}$ tricine, and $10 \mu \mathrm{M} \mathrm{Pb}(\mathrm{Zn}+$ tricine $+\mathrm{Pb}$; dotted line $)$ and introduced at the time point indicated by the arrow. (B) Bar graphs of the averaged $\mathrm{Y} / \mathrm{C}$ ratio values from Met-lead under the conditions in (A). (C) Samples of tap water from a laboratory faucet, without (Sample; solid line) or with $10 \mathrm{mM}$ of tricine added (Sample + tricine; dashed line), were placed in the Met-lead biosensing system at the time point indicated by the arrow. All experimental sample tests were with ionomycin $(5 \mu \mathrm{M})$. (D) Bar graphs of the averaged $\mathrm{Y} / \mathrm{C}$ ratio values from Met-lead under the conditions in (B).

Next, we took a tap water sample from a faucet in our laboratory as the first practical test of the sensor (Figure 5C). Using ICP-MS, this water sample was confirmed to contain a small amount of $\mathrm{Zn}(97.8 \mu \mathrm{g} / \mathrm{dL}$; lower than the U.S. EPA regulation $500 \mu \mathrm{g} / \mathrm{dL})$ and $\mathrm{Pb}$ $(9.75 \mathrm{nM}$, or $0.195 \mu \mathrm{g} / \mathrm{dL}$; lower than the WHO regulation $1 \mu \mathrm{g} / \mathrm{dL})$ (Figure S5). This water sample produced a significantly increase in the $\mathrm{Y} / \mathrm{C}$ ratio through our Met-lead biosensor, from the resting value of $2.2903 \pm 0.0609$ to $3.8879 \pm 0.0861$ (solid line in Figure 5C). When the same water sample was pre-mixed with tricine $(10 \mathrm{mM})$, this increased the $\mathrm{Y} / \mathrm{C}$ ratio of the Met-lead biosensor from $2.0512 \pm 0.0970$ to $2.6407 \pm 0.0604$ within $10 \mathrm{~min}$ (dash line in Fig. 5C; full time scale in Figure S5B). These data summarize the results of the tests with real tap water samples (Figure 5D) and suggest that Met-leads and pMet-lead can be successfully used in real-world applications. The animated data on these tricine tests are sown in Movie S1-S6. 


\subsection{Practical water check by pMet-lead}

Next, we further tested the practical application of the newly developed pMet-lead (Figure 6; Table 2). Water samples gathered from six selected regions of Taiwan (Figure 6A), including inhabited areas near Taipei city (sample I and II), Taoyuan County (sample III), Miaoli County (sample IV), Nantou County (sample V), and even the rural area of Taiwan, i.e., Dongshi Township, Yunlin County (sample VI). These water samples were placed into the pMet-lead to obtain $\mathrm{Y} / \mathrm{C}$ emission ratio color images (Figure 6B) and ratios (Figure 6C). Two of these samples had significantly higher $\mathrm{Y} / \mathrm{C}$ emission ratios $(3.4803 \pm$ 0.0839 in sample IV; $3.7431 \pm 0.1236$ in sample VI, Figure 6C) than the control set $(2.7931 \pm$ 0.025 , Table 2 ). The remaining samples had low $\mathrm{Y} / \mathrm{C}$ ratios, which were confirmed by ICPMS (Table 2) to be $\mathrm{Pb}$ negative or contain relatively low $\mathrm{Pb}$ : no lead was detected (NA) in samples I (2.3136 \pm 0.0416$)$, III $(2.4554 \pm 0.05369)$, and V $(2.3581 \pm 0.0258)$ and $0.64 \mathrm{ppb} \mathrm{Pb}$ was detected in sample II $(2.2897 \pm 0.0250)$. The samples with high $\mathrm{Y} / \mathrm{C}$ ratios were also confirmed to contain $\mathrm{Pb}$ exceeding the acceptable level (10 ppb) set by the WHO (10.6 ppb in sample IV; 15.24 in sample VI, Table 2$)$. The linearity $\left(\mathrm{R}^{2}\right)$ of ICP-MS to pMet-lead for the six selected real-world unknown samples was 0.9061 (Figure 6D). Therefore, these two samples were proven to contain $\mathrm{Pb}$. The data for the rest of the tested samples are shown in Table 2.

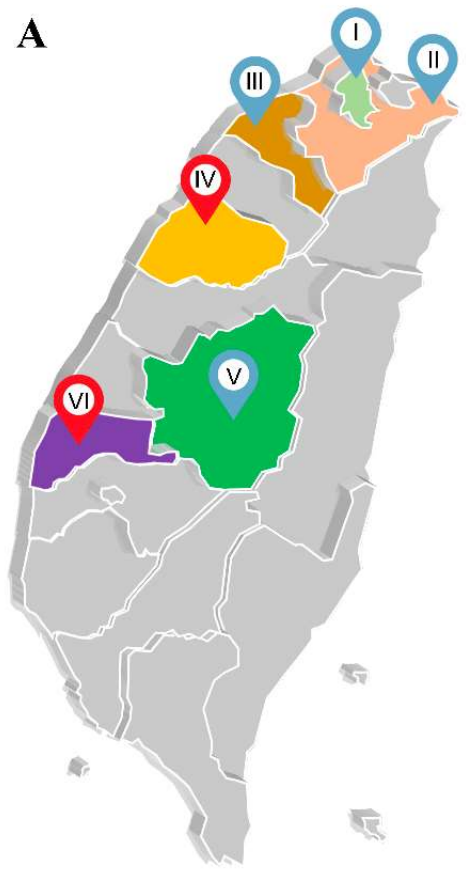

\section{B}
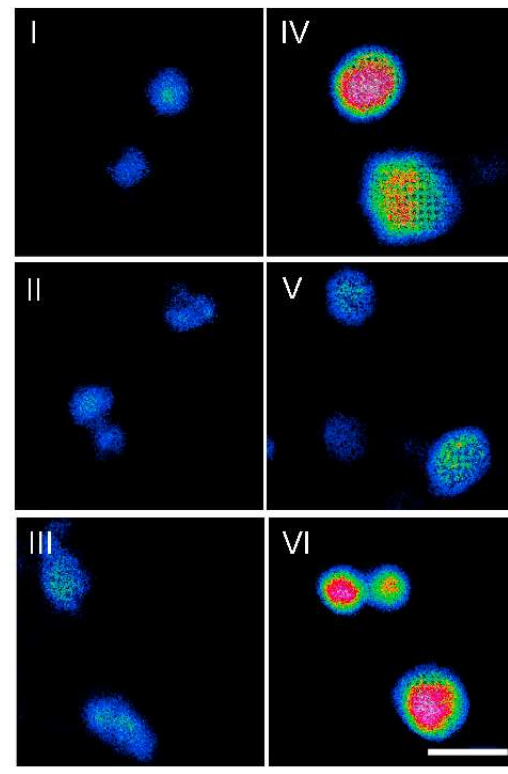
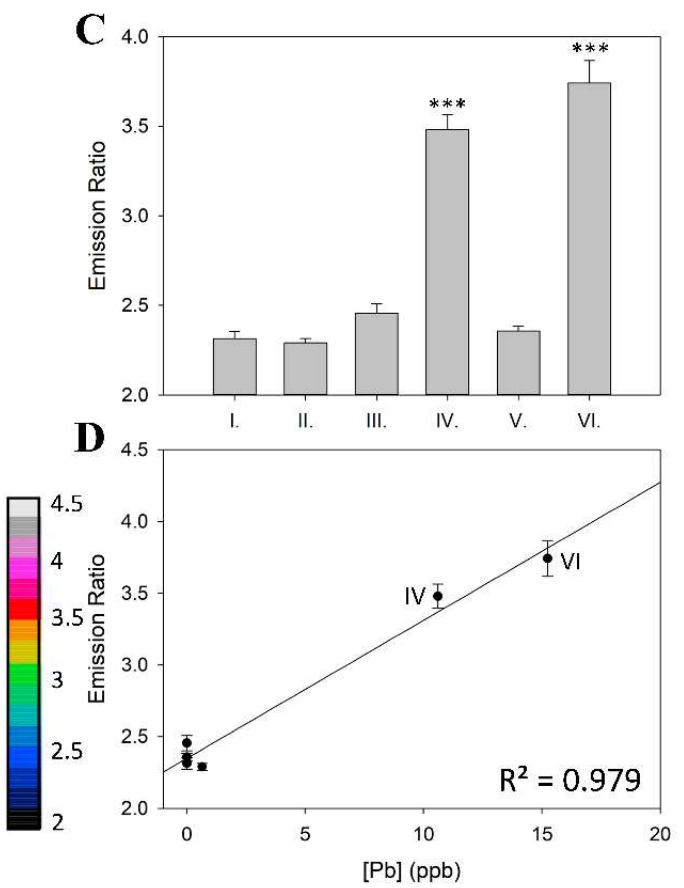

Figure 6. Measurement of $\mathrm{Pb}$ levels in selected environmental areas using the portable FRET-based Pb sensing device. (A) Geographical regions where water samples were randomly collected in selected cities of Taiwan: I. Taipei city; II. New Taipei; III. Taoyuan; IV. Miaoli; V. Nantou; VI. Yunlin. (B) Representative ratio color images of samples I-VI analyzed using pMet-lead. (C) Average ratio for each geographical region compared to control water samples. (D) pMet-lead FRET ratio values of $\mathrm{Pb}$ measurements from various geographic sources of water were validated by the general standard method (ICP-MS). Scale bar, $30 \mu \mathrm{m}$. The ratio color bar is from 2 to 4.5 .

Table 2. $\mathrm{Pb}$ detection in different water supply systems. pMet-lead FRET ratios of practical Pb measurements of various sources of water in this study (Figure 6) were validated using the general standard method (ICP-MS).

\begin{tabular}{ccc}
\hline Water samples & Mean of $\mathbf{Y} / \mathbf{C}$ ratio (with standard error) & ICP-MS (ppb) \\
\hline Control & $2.7931 \pm 0.025$ & NA $^{1}$ \\
\hline $\mathrm{I}$ & $2.3136 \pm 0.0416$ & NA \\
\hline
\end{tabular}




\begin{tabular}{ccc} 
II & $2.2897 \pm 0.0250$ & 0.64 \\
\hline III & $2.4554 \pm 0.05369$ & NA \\
\hline IV & $3.4803 \pm 0.0839\left(^{* * *}\right)^{2}$ & 10.6 \\
\hline V & $2.3581 \pm 0.0258$ & NA \\
\hline VI & $3.7431 \pm 0.1236\left({ }^{* * *}\right)^{2}$ & 15.24 \\
\hline
\end{tabular}

${ }^{1} \mathrm{NA}$ : none detected; ${ }^{2}$ The values are above the WHO 2017 cutoff for Pb in tap water of $1 \mu \mathrm{g} / \mathrm{dL}(10 \mathrm{ppb}, 50 \mathrm{nM}) ;{ }^{* * *}, \mathrm{p}<0.0005$, two-tailed t-test

\section{Discussion}

The integration of smartphones into sensing methods has been widely applied, whether in fluorescence or colorimetric systems [14, 16, 17], or through sensing chips or paper format [19-21], to fulfill demands due to the large number of users [12, 13, 18, 24, 29-31]. However, it is relatively rare to see FRET-based devices invented for the development of portable fluorescence sensing. The possible reasons for this could be: (1) two or more fluorescent signals need to be measured simultaneously, which causes a major inconvenience for hardware design of sensors for both laboratory-based and portable, smartphone-based microscopic imaging and sensing; (2) further processing procedures are required, e. g., the YFP/CFP ratios from the image data taken from the portable device require processing through the division operation; (3) the increase in the ratio representing the presence of target molecules within FRET-based biosensors is restricted to less than 10-fold, whereas typical fluorescence methods for sensing target binding can detect fluorescence increase of thousandfolds.

Despite the above disadvantages, FRET-based biosensors have some benefits for monitoring specific targets [32-36]. First, the ratios represent the meanness of normalization. This property of FRET ratio detection provides superior data for indicating the existence of a target, since there is no need to find a standard baseline, as is required for most indicators. Briefly, each fluorescent sensor emits a specific emission signal, and the increase (or decrease when it is off sensor) in the changes in the fluorescence intensity needs to be normalized in order to pool together the data, since the original intensity of each molecule and the corresponding increase in fluorescence intensity for each one is both different. This might be why Met-lead 1.44 M1 is sensitive enough to detect Pb content as low as $10 \mathrm{nM}$ [8]. Secondly, the rainbow color plate used for the presentation of FRETbased sensing is an easy way to visualize the detection results: red means polluted by $\mathrm{Pb}$, while blue means OK to drink if the tested sample is drinking water (Figure 6). Having a portable $\mathrm{Pb}$ sensing device on hand provides the immense benefit of not having to go through the costly and time-consuming process of collecting and transporting water samples to testing companies.

Long-term chronic exposure to low $\mathrm{Pb}$ could increase the risk of cardiological and neurological diseases in humans [37-42]. Currently, the only validated way to determine the $\mathrm{Pb}$ content of suspicious targets is using standard precision analytical instruments, such as ICP-MS, which are available only in hospitals or testing companies, which is costly and requires at least two weeks before results are known [2,3,43]. Thus, any kind of portable device that can monitor $\mathrm{Pb}$ in drinking water supplies, such as tap water or groundwater, would be helpful in preventing $\mathrm{Pb}$ poisoning in a community. Here, we developed a portable $\mathrm{Pb}$ sensing device that is compatible with smartphones and capable of distinguishing $\mathrm{Pb}$ from $\mathrm{Zn}$ (Figure 4) to improve the practicality of Met-leads. Furthermore, pMet-lead has relatively high performance/cost ratio (Table 3) for on-site, real-time quantitative environmental detection of $\mathrm{Pb}$ (LOD: $10 \mathrm{ppb}$ ) (Figure 2).

Table 3. $\mathrm{Pb}$ detection in different water supply systems. pMet-lead FRET ratios of practical Pb measurements of various sources of water in this study (Figure 6) were validated using the general standard method (ICP-MS).

\begin{tabular}{lllll}
\hline Methods & LOD & Report time & Performance/cost ratio & Note \\
\hline
\end{tabular}




\begin{tabular}{ccccc} 
ICP-MS & 0.003- 0.01 ppb 1 & Long (lab. /hospital) ${ }^{1}$ & Low (high price) & Gold standard \\
\hline GFAAS & $1-10 \mathrm{ppb} \mathrm{2}$ & Long (lab. /hospital) ${ }^{2}$ & Low (high price) & \\
\hline PB200 & $\sim 0.1 \mathrm{ppb} \mathrm{3}$ & Real time (on-site) & High; no expandability & Not validated \\
\hline PC2700 & $200 \mathrm{ppb}$ & Fast (lab.) & Low (poor LOD) & - \\
\hline Met-lead 1.59 & $100 \mathrm{ppb} \mathrm{(500} \mathrm{nM)}$ & Fast (lab.) & Low (poor LOD) & Not validated \\
\hline Met-lead 1.44 M1 & $2 \mathrm{ppb} \mathrm{(10} \mathrm{nM)}$ & Fast (lab.) & High; expandability & Validated (ICP-MS) \\
\hline pMet-lead (this study) & $10 \mathrm{ppb}(50 \mathrm{nM})$ & Real time (on-site) & High; expandability & Validated (ICP-MS) \\
\hline
\end{tabular}

${ }^{1}$ NIEA W313.53B, Taiwan; SGS; 3 ppb for water, 10 ppb for foods; 2 weeks for report; ${ }^{2}$ NIEA W303.51A, Taiwan; 2 weeks for report; ${ }^{3}$ http://www.cleaninst.tw/PB200.htm

Finally, the biochip containing the Met-lead 1.44 M1-expressing living cells is the best one that we can reliably provide at present, but could be optimized further. To improve portability, the biochip will be coated with purified or resuspended Met-lead proteins (lyophilized for longer storage) [17]. The solubility and multimeric nature of Met-lead might lower the $\mathrm{Pb}$ sensing ability during purification and resuspension (after lyophilization) into aqueous solution $[6,8]$. An alternative to this biochip is perhaps the single fluorescent protein version of the Met-lead biosensor, which will be a good choice in the future for better purification and storage, like previous successful case on the single fluorescent protein GCaMP Ca biosensor [44]. Another possibility is to use living bacteria expressing Metlead on their surface $[45,46]$. Such a bacteria version of the smartphone-based $\mathrm{Pb}$ device may enable the quick determination of $\mathrm{Pb}$ pollution anytime, anywhere. The limitations of using prokaryotes, such as Escherichia coli, are similar to those with human cell lines, i.e. difficulties in storing and maintaining the biochip, but bacteria can be stored in $4 \odot \mathrm{C}$ refrigerators and can have relatively prolonged metabolic activity compared to eukaryotic cells.

\section{Conclusions}

In this study, we developed a portable biosensor device, pMet-lead, for on-site $\mathrm{Pb}$ detection. Smartphones are a useful tool for running the iMet-lead app to take photos of samples; geographical information for the tested samples can also be provided along with the $\mathrm{Pb}$ ratio to improve data integrity, i.e. automatic collection of geographic information through the cellphone's GPS-based geographic systems. These benefits increase the practicality of pMet-lead by not only helping governing bodies identify and thus eliminate illegal the leakage of heavy metal lead into environmental water, but also encouraging citizens to be made aware of the status of their daily drinking water without having to spend a lot of money and wait more than two weeks to know the results. In summary, this study demonstrates the use of pMet-lead, a smartphone-compatible device for the biosensing of $\mathrm{Pb}$, as an on-site tool to detect environmental lead exposure.

Author Contributions: W.Q.L., D.M.Y. and Y.F.C. designed the smartphone-based FRET device. W.Q.L. and D.M.Y. performed both the experiments through the biosensing with Met-lead biosensor that those through the smartphone device. W.Q.L and F.N.C performed the tricine experiments. D.M.Y. wrote the manuscript, and Y.F.C. and W.C.L. co-wrote the manuscript.

Funding: This research was funded by the Ministry of Science and Technology (MOST), grant number MOST 105-2320-B-075-002, MOST 108-2745-8-075-001 and MOST 110-2320-B075-005; Taipei Veterans General Hospital, grant number V110C-018.

Acknowledgments: We are grateful to the MediaTek Foundation for being shortlisted in the 2021 competition of "Genius for Home". It is our honor to go outside the laboratory and practically do things good essentially for the people.

Conflicts of Interest: The authors declare no conflict of interest.

\section{References}


1. UNICEF (Rees, N.) \& Pure Earth (Fuller, R.) The toxic truth: children's exposure to lead pollution undermines a generation of future potential; 2020; ISBN: 978-92-806-5140-9.

2. Caldwell, K.L.; et al. Measurement challenges at low blood lead levels. Pediatrics. 2017, 140, e20170272. https://doi.org/10.1542/peds.2017-0272.

3. Caldwell, K.L.; et al. LAMP: A CDC program to ensure the quality of blood-lead laboratory measurements. J. Public Health Manag. Pract. 2019, 25, (p) S23 - S30. https://doi.org/10.1097/PHH.0000000000000886.

4. Paulson, J.A.; Brown, M.J. The CDC blood lead reference value for children: time for a change. Environ. Health. 2019, 18, 16. https://doi.org/10.1186/s12940-019-0457-7.

5. Jarvis, P.; Fawell, J. Lead in drinking water - Ann ongoing public health concern? Curr Opin Environ Sci Health. 2021, 20, 100239. https://doi.org/10.1016/j.coesh.2021.100239.

6. Chiu, T.Y.; Yang, D.M. Intracellular Pb2+ content monitoring using a protein-based Pb2+ indicator. Toxicol. Sci. 2012, 126, 436-445. https://doi.org/10.1093/toxsci/kfs007.

7. Yang, D. M.; et al. Monitoring the heavy metal lead inside living Drosophila with a FRET-based biosensor. Sensors. 2020a, 20, 1712. https://doi.org/10.3390/s20061712.

8. Yang, D. M.; et al. High-performance FRET biosensors for single-cell and in vivo lead detection. Biosen Bioelec. 2020b, 168, 112571. https://doi.org/10.1016/j.bios.2020.112571.

9. Chang, T.J.; Lai, W.Q.; Chang, Y.F.; Wang, C.L.; Yang, D.M. Development and optimization of heavy metal lead biosensors in biomedical and environmental applications. J Chin Medi Assoc. 2021, 84, 745-753. https://doi.org/10.1097/JCMA.0000000000000574.

10. Yang, D.M.; Chang, Y.F. Versatile cell and animal models for advanced investigations of lead poisoning. Biosensors. 2021, 11, 371. https://doi.org/10.3390/bios11100371.

11. World Health Organization. Guidelines for drinking-water quality, 4 th ed +1 s $t$ add. WHO: Geneva, 2017, accessed 26 May 2020; ISBN: 9789241549950.

12. Breslauer, D.N.; Maamari, R.N.; Switz, N.A.; Lam, W.A.; Fletcher, D.A. Mobile phone based clinical microscopy for global health applications. PLoS One. 2009, 22;4(7):e6320. https://doi.org/10.1371/journal.pone.0006320.

13. Smith, Z,J.; et al. Cell-phone-based platform for biomedical device development and education applications. PLoS One. 2011, 6(3), e17150. https://doi.org/10.1371/journal.pone.0017150.

14. Zhu, H.; Yaglidere, O.; Su, T. W.; Tseng, D.; Ozcan, A. Cost-effective and compact wide-field fluorescent imaging on a cell-phone. Lab Chip. 2011, 11(2), 315-22. https://doi.org/10.1039/c0lc00358a.

15. Switz, N.A.; D'Ambrosio, M.V.; Fletcher, D,A. Low-cost mobile phone microscopy with a reversed mobile phone camera lens. PLoS One. 2014, 22;9(5), e95330. https://doi.org/10.1371/journal.pone.0095330.

16. Knowlton, S.; Joshi, A.; Syrrist, P.; Coskun, A.F.; Tasoglu, S. 3D-printed smartphone-based point of care tool for fluorescence- and magnetophoresis-based cytometry. Lab Chip. 2017, 17(16), 2839-2851. https://doi.org/10.1039/c7lc00706j.

17. Chen, P.C.; et al. Rapidly and simultaneously quantifying multiple biomarkers of L-tyrosine hydroxylase deficiency by using paper microfluidic devices and smartphone-based analysis system. Sensors and Actuators B: Chemical. 2021a, 349, 130722. https://doi.org/10.1016/j.snb.2021.130722.

18. Sun, K.; Yang, Y.; Zhou, H.; Yin, S.; Qin, W.; Yu, J.; Chiu, D, T.; Yuan, Z.; Zhang, X.; Wu, C. Ultrabright Polymer-Dot Transducer Enabled Wireless Glucose Monitoring via a Smartphone. ACS Nano. 2018, 26, 5176-5184. https://doi.org/10.1021/acsnano.8b02188.

19. Calabretta, M.M.; Álvarez-Diduk, R.; Michelini, E.; Roda, A.; Merkoçi, A. Nano-lantern on paper for smartphone-based ATP detection. Biosens Bioelectron. 2020, 150, 111902. https://doi.org/10.1016/j.bios.2019.111902.

20. Sarwar, M.; Leichner, J.; Naja, G, M.; Li, C, Z. Smart-phone, paper-based fluorescent sensor for ultra-low inorganic phosphate detection in environmental samples. Microsyst Nanoeng. 2019, 5, 56. https://doi.org/10.1038/s41378-019-0096-8

21. Shan, Y.; et al. On-site quantitative $\mathrm{Hg} 2+$ measurements based on selective and sensitive fluorescence biosensor and miniaturized smartphone fluorescence microscope. Biosens Bioelectron. 2019, 132, 238-247. https://doi.org/10.1016/j.bios.2019.02.062.

22. Alam, M.W.; Wahid, K.A.; Fahmid, I.M.; Bernhard, W.; Geyer, C.R.; Vizeacoumar, F.J. A Low-Cost and Portable Smart Instrumentation for Detecting Colorectal Cancer Cells. Applied Sciences. 2019, 9(17): 3510. https://doi.org/10.3390/app9173510

23. Ng, E.; Yao, C.; Shultz, T.O.; Ross-Howe, S.; Wang, S.X. Magneto-nanosensor smartphone platform for the detection of HIV and leukocytosis at point-of-care. Nanomedicine. 2019, 16, 10-19. https://doi.org/10.1016/j.nano.2018.11.007.

24. Fozouni, P.; et al. Amplification-free detection of SARS-CoV-2 with CRISPR-Cas13a and mobile phone microscopy. Cell. 2021, 184(2), 323-333.e9. https://doi.org/10.1016/j.cell.2020.12.001.

25. Chang, Y. F.; et al. Orai1-STIM1 formed store-operated Ca2+ channels (SOCs) as the molecular components needed for Pb2+ entry in living cells. Toxicol. Appl. Pharmacol. 2008, 227, 430-439. https://doi.org/10.1016/j.taap.2007.11.025.

26. Chiu, T.Y.; Chen, P.H.; Chang, C.L.; Yang, D.M. Live-cell dynamic sensing of Cd2+ with a FRET-based indicator. PLoS One. 2013, 8, e65853. https://doi.org/10.1371/journal.pone.0065853.

27. Suwa, H.; Saint-Amant, L.; Triller, A.; Drapeau, P.; Legendre, P. High-affinity zinc potentiation of inhibitory postsynaptic 
glycinergic currents in the zebrafish hindbrain. J Neurophysiol. 2001, 85(2), 912-25. https://doi.org/10.1152/jn.2001.85.2.912.

28. Radford, R.J.; Lippard, S.J. Chelators for investigating zinc metalloneurochemistry. Curr Opin Chem Biol. 2013, 17(2), 12936. https://doi.org/10.1016/j.cbpa.2013.01.009.

29. Alawsi, T.; Al-Bawi, Z. A review of smartphone point - of - care adapter design. Engineer. Reports. 1, 2019, e12039. https://doi.org/10.1002/eng2.12039.

30. Zhao, W.; Tian, S.; Huang, L.; Guo, J.; Liu, K.; Dong, L. Smartphone-based Biomedical sensory system. Analyst. 2020, 145, 2873-2891. https://doi.org/10.1039/C9AN02294E.

31. Chen, W.; Yao, Y.; Chen, T.; Shen, W.; Tang, S.; Lee, H.K. Application of smartphone-based spectroscopy to biosample analysis: A review. Biosens Bioelectron. 2021b, 172, 112788. https://doi.org/10.1016/j.bios.2020.112788.

32. Hochreiter, B.; Pardo-Garcia, A.; Schmid, J. A. Fluorescent proteins as genetically encoded FRET biosensors in life sciences. Sensors. 2015, 15, 26281-26314. https://doi.org/10.3390/s151026281.

33. Marx, V. Probes: FRET sensor design and optimization. Nat. Methods. 2017, 14, 949-953. https://doi.org/10.1038/nmeth.4434.

34. Algar, W.R.; Hildebrandt, N.; Vogel, S.S.; Medintz, I.L. FRET as a biomolecular research tool - understanding its potential while avoiding pitfalls. Nat. Methods. 2019, 16, 815-829. https://doi.org/10.1038/s41592-019-0530-8

35. Zhang, X.; Hu, Y.; Yang, X.; Tang, Y.; Han, S.; Kang, A.; Deng, H.; Chi, Y.; Zhu, D.; Lu, Y. FÖrster resonance energy transfer (FRET)-based biosensors for biological applications. Biosen. Bioelec. 2019, 138, 111314. https://doi.org/10.1016/j.bios.2019.05.019.

36. Watabe, T.; Terai, K.; Sumiyama, K.; Matsuda, M. Booster a red-shifted genetically encoded Förster resonance energy transfer (FRET) biosensor compatible with cyan fluorescent protein/yellow fluorescent protein-based FRET biosensors and blue light-responsive optogenetic tools. ACS Sens. 2020, 5, 719-730. https://doi.org/10.1021/acssensors.9b01941.

37. Flora, G.; Gupta D.; Tiwari, A. Toxicity of lead: A review with recent updates. Interdiscip. Toxicol. 2012, 5, 47-58. https://doi.org/10.2478/v10102-012-0009-2.

38. Mitra, P.; Sharma, S.; Purohit, P.; Sharma, P. Clinical and molecular aspects of lead toxicity: An update. Crit. Rev. Clin. Lab. Sci. 2017, 54, 506-528. https://doi.org/10.1080/10408363.2017.1408562.

39. Reuben, A.; et al. Association of childhood blood-lead levels with cognitive function and socioeconomic status at age 38 years and with IQ change and socioeconomic mobility between childhood and adulthood. JAMA. 2017, 317, $1244-1251$. https://doi.org/10.1001/jama.2017.1712.

40. Lanphear, B.P.; Rauch, S.; Auinger, P.; Allen, R.W.; Hornung, R.W. Low-level lead exposure and mortality in US adults: a population-based cohort study. Lancet Public Health. 2018, 3, 177-184. https://doi.org/10.1016/S2468-2667(18)30025-2.

41. Rocha, A.; Trujillo, K. Neurotoxicity of low-level lead exposure: history, mechanisms of action, and behavioral effects in humans and preclinical models. Neurotox. 2019, 73, 58-80. https://doi.org/10.1016/j.neuro.2019.02.021

42. O'Connor, D.; Hou, D.; Ok, Y.S.; Lanphear, B.P. The effects of iniquitous lead exposure on health. Nat Sustain. 2020, 3, 7779. https://doi.org/10.1038/s41893-020-0475-z.

43. Frank, J. J.; Poulakos, A. G.; Tornero-Velez R.; Xue, J. Systematic review and meta-analyses of lead (Pb) concentrations in environmental media (soil, dust, water, food, and air) reported in the United States from 1996 to 2016. Sci. Total Environ. 2019, 694, 133489. https://doi.org/10.1016/j.scitotenv.2019.07.295.

44. Akerboom, J.; et al. Optimization of a GCaMP calcium indicator for neural activity imaging. J Neurosci. 2012, 32(40): 13819-13840. https://doi.org/10.1523/JNEUROSCI.2601-12.2012

45. Wu, M.L.; Tsai, C.Y.; Chen, T.H. Cell surface display of Chi92 on Escherichia coli using ice nucleation protein for improved catalytic and antifungal activity. FEMS microbiology letters. 2006, 256(1), 119-125. https://doi.org/10.1111/j.15746968.2006.00115.x.

46. Matsuura, H.; et al. Development of surface-engineered yeast cells displaying phytochelatin synthase and their application to cadmium biosensors by the combined use of pyrene-excimer fluorescence. Biotechnology progress. 2013, 29(5), 1197-1202. https://doi.org/10.1002/btpr.1789. 